\title{
Self-driven Gate Driver for LLC Synchronous Rectification
}

\author{
Li, Mingxiao; Ouyang, Ziwei; Andersen, Michael A. E.; Zhao, Bin
}

Published in:

IEEE Transactions on Power Electronics

Link to article, DOI:

10.1109/TPEL.2020.3003417

Publication date:

2020

Document Version

Peer reviewed version

Link back to DTU Orbit

Citation (APA):

Li, M., Ouyang, Z., Andersen, M. A. E., \& Zhao, B. (2020). Self-driven Gate Driver for LLC Synchronous Rectification. IEEE Transactions on Power Electronics, 36(1), 56 - 60.

https://doi.org/10.1109/TPEL.2020.3003417

\section{General rights}

Copyright and moral rights for the publications made accessible in the public portal are retained by the authors and/or other copyright owners and it is a condition of accessing publications that users recognise and abide by the legal requirements associated with these rights.

- Users may download and print one copy of any publication from the public portal for the purpose of private study or research.

- You may not further distribute the material or use it for any profit-making activity or commercial gain

- You may freely distribute the URL identifying the publication in the public portal

If you believe that this document breaches copyright please contact us providing details, and we will remove access to the work immediately and investigate your claim. 


\title{
Self-driven Gate Driver for LLC Synchronous Rectification
}

\author{
Mingxiao Li, Student Member, IEEE, Ziwei Ouyang, Senior Member, IEEE, Michael A. E. Andersen, Member, IEEE \\ and Bin Zhao, Member, IEEE
}

\begin{abstract}
This letter proposes a self-driven gate driver solely composed of passive components for synchronous rectification (SR). It utilizes the energy of the converter itself, automatically considers component tolerances and temperature variations of critical design parameters, and tunes the SRs on-time. Furthermore, no microcontroller, auxiliary power supply or current-sensing/voltage-sensing components is required. A great amount of cost is therefore saved. The proposed gate driver is preferable to be used to any resonant converters operating as DC transformers. This letter presents its practical implementation in an LLC resonant converter. Experiment results illustrate that the body diodes conduction and reverse recovery are eliminated.
\end{abstract}

\section{INTRODUCTION}

Converters used for low voltage high current applications generally require synchronous rectification for the secondary side devices to improve the total system efficiency. For instance, the LLC resonant converter, as shown in Fig.1, benefits from zero-voltage-switching (ZVS) for primary switches and zerocurrent-switching (ZCS) for secondary synchronous rectifiers (SRs). It is often operating as a DC transformer whose switching frequency is the resonant frequency to achieve peak efficiency. A deal of research was conducted to improve SR driving schemes [1]-[14]. These driving schemes can be generally grouped into current sensing-based and voltage sensing-based methodologies. Large power loss is induced by the current sensing-base SR driving scheme due to additional current sensing components [1]-[3]. The accuracy of the voltage sensing solution is highly sensitive to the circuit parasitic inductance [4]-[9]. Publications [6]-[9] present an adaptive algorism processed in a microcontroller. These driving schemes either add the system complexity or increase the cost. Commercial SR driving controllers [10]-[13] based on voltagesensing schemes cannot achieve high-frequency operation causing by the propagation delay.

This paper proposes a new driving scheme: the driving signals $V_{g s} S R$ for the secondary SRs are generated from the drain-source voltage $V_{d s} S R$. The auxiliary passive components create a resonant tank to extract the first harmonic of $V_{d s} S R$ with a 180-degree phase shift to create the gate signal $V_{g S} S R$. This principle automatically considers component tolerances and temperature changes of critical design parameters [15]. It eliminates the body diodes conduction, and reverse recovery. Furthermore, no microcontroller or current-sensing/voltagesensing components is required, thus significantly reducing the cost.
The remainder of this paper is organized as follows: The operating principle is given in Section II. Section III illustrates the design considerations to implement it practically in an LLC resonant converter. Section IV shows the experimental results of the LLC resonant converter using this passive gate driver. Section V concludes the paper.

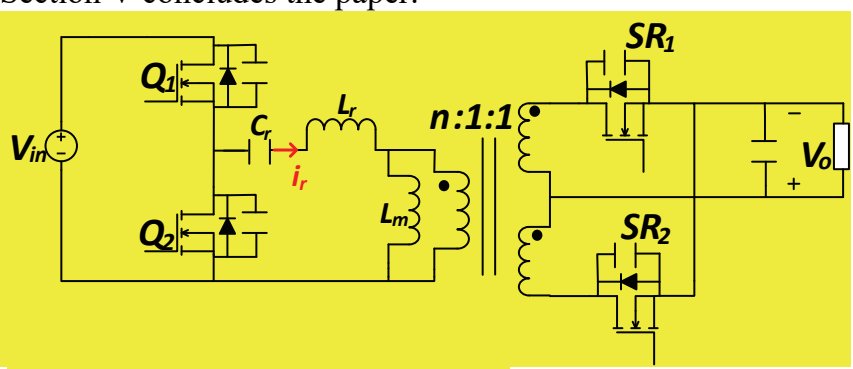

Fig.1 Topology of the LLC resonant converter

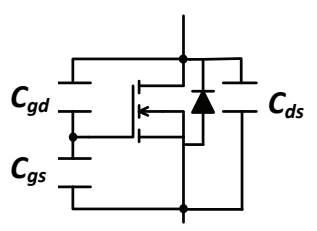

(a)

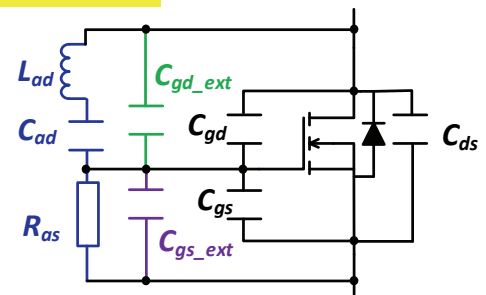

(b)
Fig.2 (a) Circuit model of MOSFET and (b) proposed synchronous driving scheme

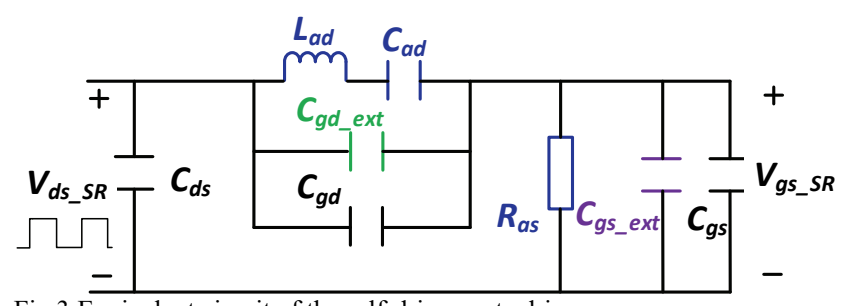

Fig.3 Equivalent circuit of the self-driven gate driver

\section{OPERATING PRINCIPLE}

The circuit diagram shown in Fig.2(a) illustrates a MOSFET with its parasitic capacitances, $C_{d s}, C_{g s}$ and $C_{g d}$. The proposed synchronous driving scheme is only constituted by 3 passive components, $L_{a d}, C_{a d}$, and $R_{a s}$, optional with additional MOSFET's capacitances $C_{g d \_ \text {ext }}, C_{g g_{-} \text {ext }}$ as shown in Fig.2 (b). No auxiliary power supply is needed. Generally, the gate signal $V_{g s_{-} S R}$ is generated from the square wave $V_{d s_{-} S R}$. The added components compose a resonant tank. It attenuates the first harmonic of $V_{d S_{-} S R}$ with the 180-degree phase shift to adequate value to create the $V_{g S_{-} S R}$. Other higher-order harmonics are 


\section{IEEE POWER ELECTRONICS REGULAR PAPER/LETTER/CORRESPONDENCE}

highly attenuated and negligible. Detailed operating analyses are given as follows.

Fig.3 shows an equivalent circuit of the proposed driving scheme. The square wave $V_{d s} S R$ is seen as the input voltage source and the $V_{g s} S_{R}$ is taken as the output. $C_{d s}, C_{g s}$ and $C_{g d}$ are inherent capacitances of the MOSFET. $L_{a d}, C_{a d}, C_{g d \_ \text {ext }}, C_{g s_{-} e x t}$ and $R_{a s}$ are auxiliary passive components. The following equations (1) and (2) represent the transfer function $G$ from the output $V_{g s_{-} S R}$ to the input $V_{d s_{-} S R}$, and input impedance $Z_{i n}$, respectively. Two resonant frequencies $f_{r 1}$ and $f_{r 2}$ can be solved by setting the input impedance $Z_{i n}$ to be zero: $L_{a d}, C_{a d}, C_{g s_{-} \text {ext }}$ and $C_{g s}$ form the first resonant frequency $f_{r 1} ; C_{g d}, C_{g d}$ ext and $\bar{L}_{a d}$ constitute the second resonant frequency $f_{r 2}$. The bode plot of the transfer function $G$ is shown in Fig.4. As mentioned before, 180-degree out of the phase with respect to the $V_{d S_{S} S R}$ at the switching frequency is expected for the $V_{g s_{-} S R}$ to achieve synchronous rectification. It can be seen that there is a 180 degree phase shift in the region between $f_{r 1}$ and $f_{r 2}$, where the fundamental harmonic frequency $f_{r}$ of the $V_{d S_{-} S R}$ is involved.

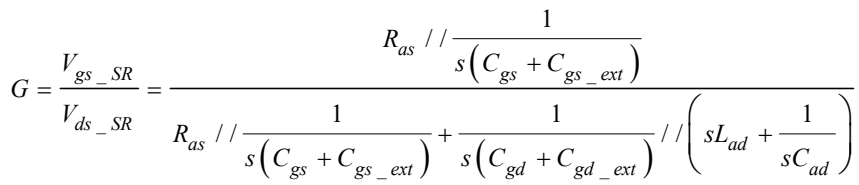

$$
Z_{\text {in }}=R_{a s} / / \frac{1}{s\left(C_{g s_{1}}+C_{g s_{-} e x t}\right)}+\frac{1}{s\left(C_{g d_{1}}+C_{g d_{-} e x t}\right)} / /\left(s L_{a d}+\frac{1}{s C_{a d}}\right)
$$

$$
f_{r 1}=\frac{1}{2 \pi \sqrt{L_{a d} \cdot\left(C_{g s}+C_{g s_{-} e x t}\right) / / C_{a d}}}, f_{r 2}=\frac{1}{2 \pi \sqrt{L_{a d}\left(C_{g d}+C_{g d_{-} e x t}\right)}}
$$

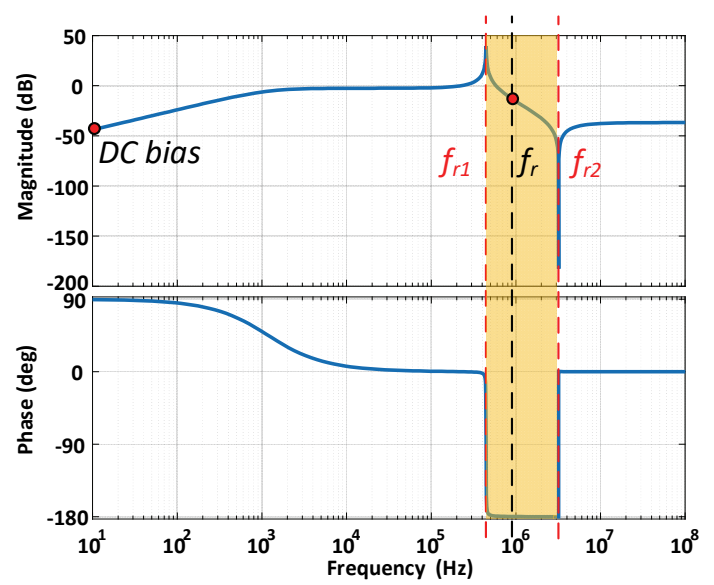

Fig.4 Typical bode plot of the transfer function $G$

Additionally, considering the MOSFET safe operation, the peak-to-peak gate-source voltage must be designed in a safe range. It contains the DC offset and a sine voltage swing (the attenuated first harmonic of $\left.V_{d s_{-}} S R\right)$. The DC offset can be used to change the duty cycle. Fig.5 shows two gate signals: one with DC offset and the other without DC offset. Higher DC offset yields a larger duty cycle. The resistor $R_{a s}$ can be used to control this DC offset. As the LLC resonant converter is operating at a fixed $50 \%$ duty cycle, the DC offset is not required for the SRs' gate signal. It can be eliminated by choosing a smaller $R_{a s}$. As mentioned earlier, the passive gate driver should be designed to attenuate the first harmonic of $V_{d S_{-} S R}$ with a 180-degree phase shift to adequate value. This means that the amplitude of the sine voltage swing must be lower than the MOSFET maximum allowed gate-to-source voltage, which can be calculated by (4).

$$
V_{g s_{-} S R}\left(f_{r}\right)=V_{d s_{-} S R} \cdot 10^{\frac{G\left(\mathrm{j} \cdot 2 \pi f_{r}\right)}{20}}
$$

Other higher-order harmonics located on $f_{r}$ right side are not considered, because they suffer much larger attenuation than the fundamental harmonic, as shown in Fig. 4. Therefore, these higher-order harmonics have extremely low amplitude and negligible effect on the gate signal.

Based on the above discussions, the passive gate driver should be designed to satisfy three requirements: 1) the fundamental harmonic frequency of $V_{d S_{S} S R}$ is located in the region between the two resonant frequencies $f_{r 1}$ and $f_{r 2}$ where the phase shift is close to 180-degree; 2) the fundamental harmonic of $V_{d S_{-} S R}$ is attenuated to adequate value for the MOSFET safe operation, which can be calculated by (4); 3) The DC bias is well attenuated.

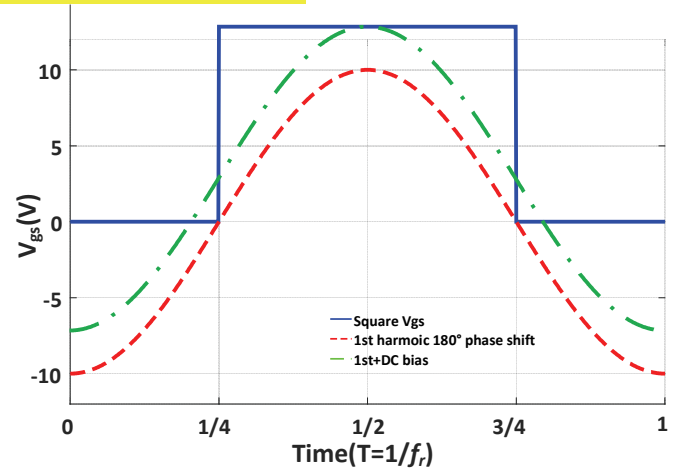

Fig.5 Two gate signals comparison

TABLE I

SPECIFICATION

\begin{tabular}{lll}
\hline \hline Symbol & Quantity & Value \\
\hline$V_{\text {in }}$ & Input voltage & $30 \mathrm{~V}$ \\
$V_{o}$ & Output voltage & $5 \mathrm{~V}$ \\
$P_{o}$ & Output power & $75 \mathrm{~W}$ \\
\hline \hline
\end{tabular}

TABLE II

CIRCUIT PARAMETERS

\begin{tabular}{ll}
\hline \hline Circuit parameters & Value \\
\hline$Q_{1} \sim Q_{2}$ & BSZ034N04LS \\
$S R_{1} \sim S R_{2}$ & BSC009NE2LS5I \\
Magnetizing inductance $L_{m}$ & $9 \mathrm{uH}$ \\
Resonant inductance $L_{r}$ & $40 \mathrm{nH}$ \\
Resonant capacitance $C_{r}$ & $2.35 \mathrm{uF}$ \\
Resonant frequency & $500 \mathrm{kHz}$ \\
Transformer & $\mathrm{n}: 1: 1=3: 1: 1$ \\
& ER18/3.2/10-ML91S \\
\hline \hline
\end{tabular}

\section{DESIGN CONSIDERATIONS}

A design example of the LLC resonant converter as a DC transformer is given in this section. Table I gives the design specification and Table II illustrates detailed circuit parameters. The maximum drain-to-source voltage $V_{d s_{S} S R}$ for SRs is $10 \mathrm{~V}$. 
The passive components should be designed with a given MOSFET and specification. From (3), the inductor $L_{a d}$ should be designed with the consideration of $f_{r 1}$ and $f_{r 2}$, as they are both controlled by this auxiliary inductor. Additionally, the capacitor $C_{g s \text { ext }}$ in parallel with $C_{g s}$ can be used to adjust the resonant frequency $f_{r 1}$. Likewise, the resonant frequency $f_{r 2}$ can be changed by $C_{g d}$ ext connected in parallel with $C_{g d}$. Nevertheless, it is not mandatory to add the two capacitors $C_{g s}$ ext and $C_{g d}$ ext to the circuit unless the fundamental harmonic frequency is not covered in the region between the two resonant frequencies $f_{r I}$ and $f_{r 2}$. The DC bias of $V_{g s} S R$ can be controlled by the resistor $R_{a s}$ and thus change the duty cycle. As mentioned before, the LLC resonant converter is operating at a fixed $50 \%$ duty cycle. The DC bias is not required and can be eliminated by choosing a smaller $R_{a s}$.

Ltspice simulation is a faster and more practical approach to design the circuit parameters compared to analytical calculation, considering the non-linear behavior of MOSFET parasitic capacitances. The auxiliary passive components are designed after a series of simulations, as documented in Table IV. Fig.6 gives the bode plot of $G$ from the small-signal analysis performed in Ltspice. Table $\mathrm{V}$ represents detailed characteristics. It is evident to see that the designed parameters satisfy all the requirements as mentioned above: The phase shift is close to 180 -degree at the resonant frequency $f_{r}$; The fundamental harmonic is involved in the region formed by $f_{r l}$ and $f_{r 2}$; The DC bias is well attenuated; $G\left(j 2 \pi f_{r}\right)$ is in a safe region.

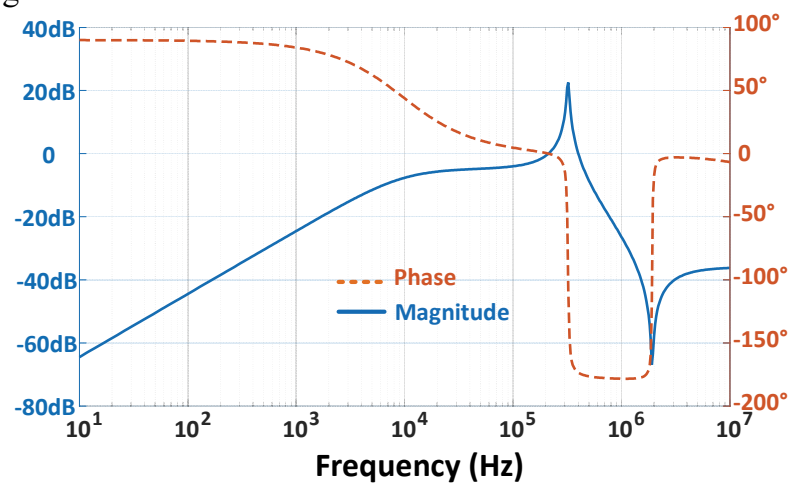

Fig.6 Bode plot of $V_{g s}$ with designed circuit parameters

TABLE IV

PARAMETERS OF THE GATE DRIVER

\begin{tabular}{cl}
\hline \hline Circuit parameters & Value \\
\hline Lad & $12 \mathrm{uH}$ \\
$C_{a d}$ & $47 \mathrm{nF}$ \\
$C_{\text {gd_ext }}$ & 0 \\
Ras $_{\text {Cost }}$ & $200 \Omega$ \\
$C_{g s}$ ext & $33 \mathrm{nF}$ \\
\hline \hline
\end{tabular}

TABLE V

CHARACTERISTICS OF THE BODE PLOT

\begin{tabular}{cl}
\hline \hline Characteristics & Value \\
\hline$f_{r 1}$ & $350 \mathrm{kHz}$ \\
\hline$f_{r}$ & $500 \mathrm{kHz}$ \\
$f_{r 2}$ & $2 \mathrm{MHz}$ \\
$G\left(j 2 \pi f_{r}\right)$ & $-8 \mathrm{~dB}$ \\
\hline \hline
\end{tabular}

\section{EXPERIMENT VERIFICATION}

The LLC resonant converter is built to verify the proposed gate driver for synchronous rectification. Fig.7 shows the gate signal and drain-to-source voltage of $Q_{2}$ along with resonant current waveform $i_{r}$ and gate signal for $S R_{2} . Q_{2}$ realizes ZVS soft-switching. Due to the feature of half-bridge configuration, $Q_{1}$ also realizes ZVS soft-switching. Fig.8 presents driving signals for $S R_{1}$ and $S R_{2}$. It can be seen that the self-driven gate driver works very well. The two gate signals automatically oscillate 180-degree out of phase with the drain-source voltage and toggle complementarily with respect to each other. The efficiency curve of the LLC resonant converter is shown in Fig.9. It achieves the $96.2 \%$ peak efficiency.

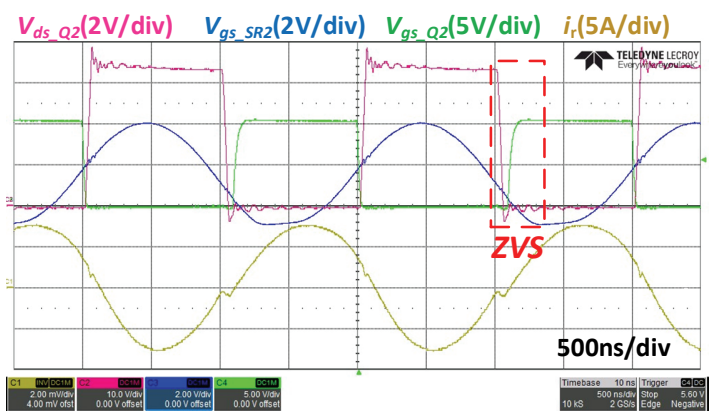

Fig.7 ZVS soft-switching waveform of Q2 at full load

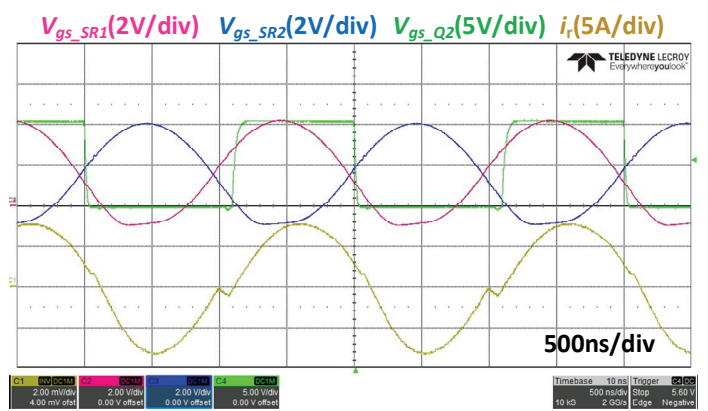

Fig.8 Driving signals for $S R_{1}$ and $S R_{2}$

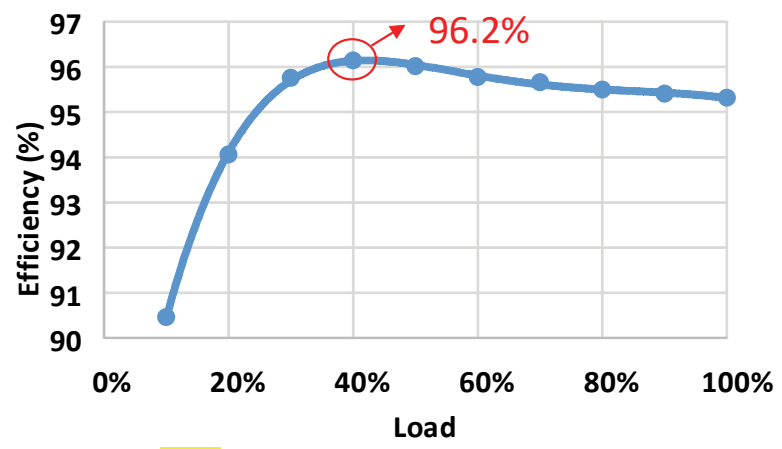

Fig.9 Efficiency curve of the LLC resonant converter

To prove the proposed gate driver eliminates the body diode conduction, this paper makes a comparison with the converter employing the traditional low side gate drivers Si8271 whose gate signals are in phase with primary switches. The forward voltage drop of the body diode is $0.5 \mathrm{~V}$, as shown in Fig. 10 . $100 \mathrm{~ns}$ body diode conduction due to the propagation delay is detected for the converter with the gate driver Si8273. By contrast, no body diode conduction appears for the converter 


\section{IEEE POWER ELECTRONICS REGULAR PAPER/LETTER/CORRESPONDENCE}

employing the proposed gate driver at either light load (10\% of the full load) or full load condition.

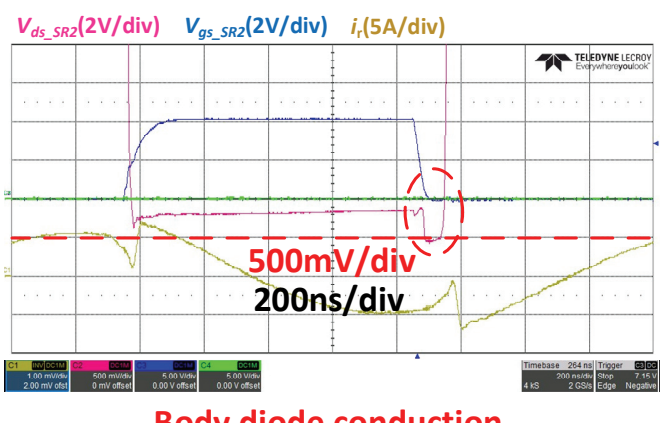

Body diode conduction

(a)

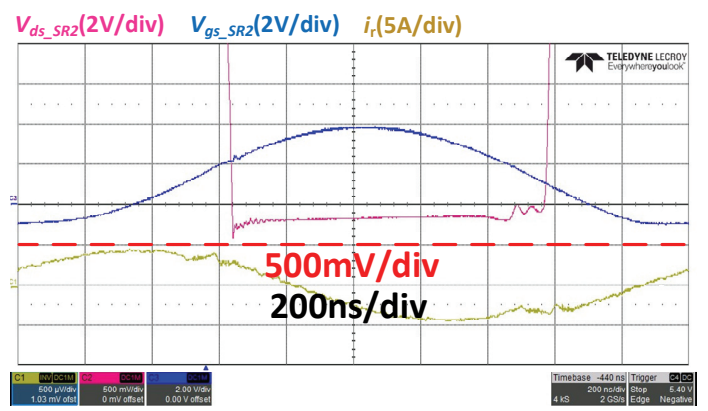

No body diode conduction

(b)

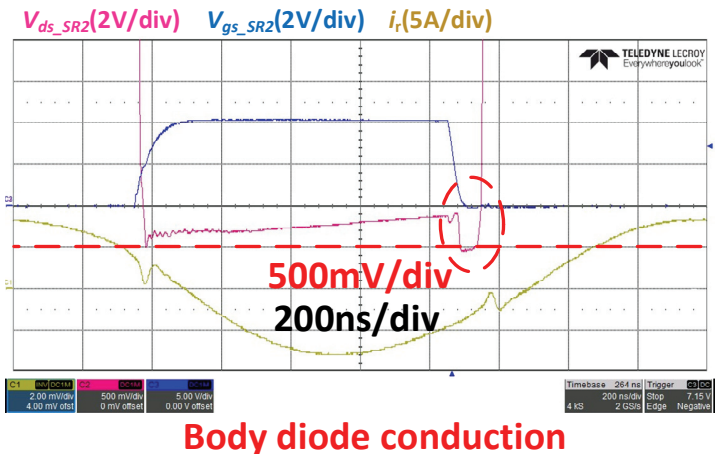

(c)

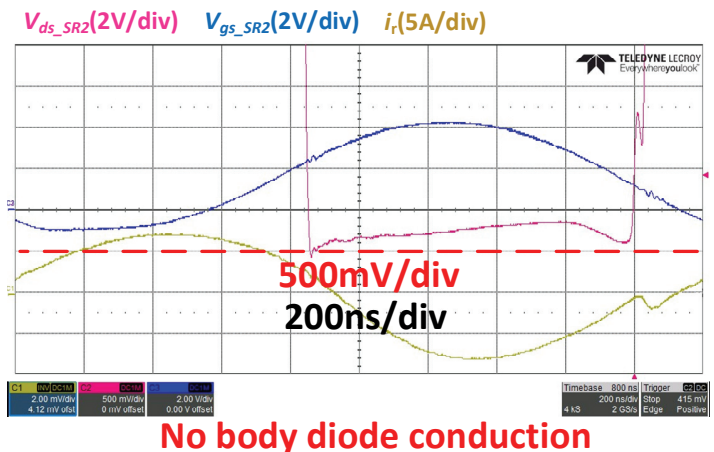

(d)

Fig. 10 Measurement of body diode conduction at (a) 10\% load with Si8271, (b) $10 \%$ load with the passive gate driver, (c) full load with Si8271, and (d) full load with the passive gate driver

\section{CONCLUSION}

This letter proposes a synchronous driving scheme primarily for resonant converters working as DC transformers, and presents its design considerations and practical implementation on and an LLC resonant converter. Unlike conventional current sensing-based and voltage sensing-based SR driving solutions, it benefits from low cost and reliable solution only constituted by passive components. Furthermore, the proposed SR scheme is not affected by the circuit parasitic components and automatically tunes the SR on-time in different load conditions.

\section{REFERENCES}

[1] X. Xie, J. Liu, F. N. K. Poon, and M. Pong, "A novel high frequency current-driven SR applicable to most switching topologies," IEEE Trans. Power Electron., vol. 16, no. 5, pp. 635-648, Sep. 2001.

[2] D. Huang, D. Fu, and F. C. Lee, "High switching frequency, high efficiency CLL resonant converter with synchronous rectifier," in Proc. IEEE Energy Convers. Congr. Expo., 2009, pp. 804-809.

[3] X. Wu, G. Hua, J. Zhang, and Z. Qian, "A new current-driven synchronous rectifier for series-parallel resonant (LLC) DC-DC converter," IEEE Trans. Ind. Electron., vol. 58, no. 1, pp. 289-297, Jan. 2011.

[4] D. Fu, Y. Liu, F. C. Lee, and M. Xu, "A Novel Driving Scheme for Synchronous Rectifiers in LLC Resonant Converters," IEEE Transactions on Power Electronics, vol. 24, no. 5, pp. 1321-1329, 2009.

[5] W. Feng, F. C. Lee, P. Mattavelli, and D. Huang, "A Universal Adaptive Driving Scheme for Synchronous Rectification in LLC Resonant Converters," IEEE Transactions on Power Electronics, vol. 27, no. 8, pp. 3775-3781, 2012.

[6] C. Fei, Q. Li, and F. C. Lee, "Digital Implementation of Adaptive Synchronous Rectifier (SR) Driving Scheme for High-Frequency LLC Converters With Microcontroller," IEEE Transactions on Power Electronics, vol. 33, no. 6, pp. 5351-5361, 2018.

[7] J.-D. Hsu, M. Ordonez, W. Eberle, M. Craciun, and C. Botting, "LLC Synchronous Rectification Using Resonant Capacitor Voltage," IEEE Transactions on Power Electronics, vol. 34, no. 11, pp. 10970-10987, 2019.

[8] L. Cheng, T. Liu, H. Gan, and J. Ying, "Adaptive synchronous rectification control circuit and method thereof," U.S. Patent 7495 934, Feb. 24, 2009.

[9] W. Feng, F. C. Lee, P. Mattavelli, and D. Huang, "A universal adaptive driving scheme for synchronous rectification in LLC resonant converters," IEEE Trans. Power Electron., vol. 27, no. 8, pp. 3775-3781, Aug. 2012

[10] International Rectifier, "IR11682S: DUAL SmartRectifier DRIVER IC," International Rectifier, El Segundo, CA, USA, Jul. 2011. [Online]. Available:http://www.irf.com/product-info/datasheets/data/ir11682spbf.

[11] STMicroelectronics, "Synchronous rectifier smart driver for LLC resonant converters," STMicroelectronics, Geneva, Switzerland, Aug. 2013.[Online].Available:http://www.st.com/content/ccc/resource/techni cal/document/datasheet/92/bd/14/1b/99/25/4f/f6/CD00282226.pdf/files/ CD00282226.pdf/jcr:content/translations/en.CD00282226.pdf

[12] NXP Semiconductors, "TEA1795T: GreenChip synchronous rectifier controller," NXP Semiconductors, Eindhoven, The Netherlands, Nov. 2010. [Online]. Available: http://www.nxp.com/documents/data_sheet/ TEA1795T.pdf

[13] Texas Instruments, "UCD7138 4-A and 6-A single-channel synchronous rectifier driver with body-diode conduction sensing and reporting,"Texas Instruments, Dallas, TX, USA, May 2015. [Online]. Available:http://www.ti.com/lit/ds/symlink/ucd7138.pdf

[14] M. P. Madsen, J. A. Pedersen, A. Knott, and M. A. E. Andersen, "Self oscillating resonant gate drive for resonant inverters and rectifiers composed solely of passive components," in Proc. IEEE Appl. Power Electron. Conf., Mar. 2014, pp. 2029-2035.

[15] Z. Ouyang, B. Zhao and M. A.E. Andersen, "Self-oscillating resonant gate driver for Synchronous Rectifier Circuits," EP Patent no. 19155153.0, February 2019, DTU ref. 96170 